\title{
Parental view of epilepsy in Angelman syndrome: a questionnaire study
}

\author{
M Ruggieri, M A McShane
}

\begin{abstract}
Purpose-To explore parents' opinions and concerns about seizures, anticonvulsants, and the effect of treatment in children with Angelman syndrome.

Design-A postal questionnaire was sent to members of one of the UK lay groups for Angelman syndrome (ASSERT) who had a child affected by Angelman syndrome. The questionnaire requested general medical information and information about the epilepsy, its treatment, and treatment responses.
\end{abstract}

Results-One hundred and fifty questionnaires were sent out with an ASSERT routine mailing and 78 completed questionnaires were returned. Forty three patients were boys and 35 were girls; ages ranged from 1.7 to 25 years (mean 7.5 years). The overall general clinical and cytogenetic data were mostly consistent with previous reports. Epilepsy was reported in 68 children, most of whom had a detectable cytogenetic deletion. The most common seizure types reported by the families were absence seizures, tonic clonic seizures, drop attacks, and myoclonic seizures; in four patients only febrile seizures occurred. The age at onset of the seizures was $<2$ years in more than half of the patients. Antiepileptic drug treatment with valproate (VPA), clonazepam (CZP), and lamotrigine (LTG) as monotherapy or a combination of VPA and CZP or VPA and LTG was more often viewed favourably and considered effective with fewer side effects on the child's behaviour and alertness, versus more frequent adverse effects and increased frequency and severity of seizures with carbamazepine (CBZ) and vigabatrin (VGB) in monotherapy or in combination with other anti-epileptic drugs. Seizures did tend to improve with age but were still present and disabling at older ages.

Conclusions-This is the first study to record parents' opinions about seizures, anti-epileptic drugs, and treatment responses in children with Angelman syndrome, and it is one of the largest series on epilepsy and Angelman syndrome to be reported to date.

(Arch Dis Child 1998;79:423-426)

Keywords: Angelman syndrome; epilepsy; seizures; parental opinions; questionnaire
Angelman syndrome ${ }^{1}$ (MIM 105830) ${ }^{2}$ is a neurogenetic disorder caused by deficiency of gene expression from maternally derived chromosome $15 \mathrm{q} 11-13 \cdot{ }^{1-4}$ Molecular analysis distinguishes four groups of Angelman syndrome patients with the following findings: (1) large (3-4 Mb) maternal deletions of $15 q 11-13(60-70 \%)$; (2) paternal uniparental disomy (5\%); (3) imprinting mutations (2-3\%); and (4) non-deletion/nonuniparental disomy/non-imprinting mutations (25-30\%). Recent studies ${ }^{56}$ have demonstrated a possible abnormality in ubiquitinassociated protein (UBE3/E6-AP) degradation during brain development in Angelman syndrome.

The prevalence of Angelman syndrome has been estimated to be $\sim 1: 10000-20000$. $^{7-9}$ Affected children have severe developmental delay, absent speech or very poor language skills, paroxysms of inappropriate laughter/ smiling, hyperactivity, and some distinct facial anomalies such as microbrachycephaly, midfacial hypoplasia, macrostomia, widely spaced teeth, protrusion of the tongue, alternating strabismus, mandibular prognathism, and signs of hypopigmentation. ${ }^{134610-14}$ Almost all present with a characteristic "puppet-like"1 motor pattern consisting of ataxic gait, tremulousness, and jerky limb movements, related to a unique pattern of fast bursting cortical myoclonus. ${ }^{15}$

Most children with Angelman syndrome have characteristic electroencephalographic (EEG) abnormalities and a history of convulsions that are difficult to characterise and to manage. ${ }^{34610-14}$ Although there are many reports on clinical and EEG features of seizures in Angelman syndrome, ${ }^{3}{ }^{40-23}$ little is known of the evolution of epilepsy. ${ }^{24}{ }^{25}$ On the other hand, to the best of our knowledge, no Angelman syndrome study has specifically recorded parents' views about their child's seizures and anticonvulsants, or about the effects of treatment. ${ }^{10-25}$

To obtain more information about the incidence and evolution of epilepsy, patterns of seizures, treatment responses, and anti-epileptic drug side effects in children with Angelman syndrome, we performed a study using a parental medical questionnaire in an informed group of families with a child affected by Angelman syndrome, through one of the UK lay groups for Angelman syndrome (Angelman syndrome support education and research trust (ASSERT)). 
Table 1 Clinical and cytogenetic features of 78 patients with Angelman syndrome

\begin{tabular}{ll}
\hline Sex $(\mathrm{M} / \mathrm{F})$ & $43 / 35$ \\
Age (mean; range) & 7.5 years; $1.7-25$ years \\
Age at diagnosis (mean; range) & 3.3 years; 8 months to 23 years \\
Cytogenetic findings & \\
Molecular deletion at chromosome 15q11-13 & $53(30 \mathrm{M} ; 23 \mathrm{~F})$ \\
Uniparental disomy & $5(2 \mathrm{M} ; 3 \mathrm{~F})$ \\
Non-deletion/non-disomy type & $9(4 \mathrm{M} ; 5 \mathrm{~F})$ \\
Data not given & $11(8 \mathrm{M} ; 3 \mathrm{~F})$ \\
\hline
\end{tabular}

\section{Patients, materials, and methods} STUDY DESIGN

In June 1996, after completing a pilot parental questionnaire study on 20 families, ${ }^{26}$ we mailed a questionnaire with an information sheet to the 150 members of ASSERT with a child affected by Angelman syndrome.

The questionnaire requested information about the diagnosis, investigations including cytogenetic data, general health, and common medical and behavioural problems associated with Angelman syndrome, as well as surgical procedures. More specific information about seizures, epilepsy, and treatment was sought using tables and simple questions.

A simplified description of seizure types classified according to the International League Against Epilepsy's classification of epileptic seizures ${ }^{27} 28$ was provided, and parents were asked to attempt to classify their child's seizures. A list of the commonly available antiepileptic drugs in the UK was given. Parents were asked to complete a simple scoring system on the effect of drugs on fit frequency, severity, and the child's alertness and behaviour.

Ethical approval for this study was obtained from the central Oxford research ethics committee (COREC).

\section{Results}

By November 1996, 78 completed questionnaires were returned. Table 1 summarises the basic composition of the group and their cytogenetic data.

Forty three patients were boys and 35 were girls. Age ranged from 1.7 to 25 years, with an average age of 7.5 years (mean age was 6.5 years for boys and 8.8 years for girls). Age at diagnosis ranged from 8 months to 23 years, with an average age of 3.3 years (mean age was 2.6 years for boys and 4.0 years for girls). Parents reported that the diagnosis was confirmed in 39 patients by a consultant geneticist, in 25

Table 2 Parental classification of seizure type and frequency in 65/68 patients ${ }^{*}$ with Angelman syndrome and epilepsy

\begin{tabular}{llll}
\hline & \multicolumn{2}{l}{ Seizures occurring } & Frequency of \\
\cline { 2 - 3 } Type of seizure & $\begin{array}{l}\text { Monthly or } \\
\text { more }(n)\end{array}$ & $\begin{array}{l}\text { Less } \\
\text { often (n) }\end{array}$ & $\begin{array}{l}\text { eache } \\
\text { type (\%) }\end{array}$ \\
\hline Tonic clonic & 15 & 23 & 58.4 \\
Infantile spasms & 5 & 3 & 12.3 \\
Drop attacks & 23 & 14 & 57.0 \\
Absence & 30 & 15 & 69.2 \\
Myoclonic & 17 & 11 & 43.0 \\
Non-convulsive status & 10 & 14 & 37.0 \\
Convulsive status & 5 & 10 & 23.0 \\
Complex partial & 5 & 4 & 14.0 \\
$>$ 2 types of seizures & 26 & 20 & 70.7 \\
\hline
\end{tabular}

*Only 65 families attempted to classify seizure type. by a consultant paediatrician, in four by a consultant paediatric neurologist, in three by a neurologist, and in six by other medical specialists; no information was given by one family.

Other than epilepsy, common additional medical problems were squint $(n=40)$, hearing difficulties related to middle ear infections $(\mathrm{n}=44)$, constipation ( $\mathrm{n}=37)$, vomiting $(\mathrm{n}=32)$, scoliosis $(\mathrm{n}=15)$, urinary infections $(n=12)$, and chest infections $(n=10)$. No additional medical problems were reported in nine children.

The most common surgical procedures reported were tonsillectomy and/or adenoidectomy ( $\mathrm{n}=18)$, placement of middle ear grommets $(n=6)$, squint surgery $(n=6)$, inguinal hernia surgery $(n=5)$, gastrostomy $(n=4)$, scoliosis correction $(n=3)$, and tendon surgery $(n=2) ; 42$ patients required no surgery.

Families considered their child's general health as good or stable in 52 and poor in three. Comments on health were not given by 23 families.

\section{EPILEPSY QUESTIONNAIRE}

Epilepsy was reported in 62 (37 boys and 25 girls) of 78 children and in a further four (two boys and two girls) only febrile seizures occurred. Six children (two boys and four girls) had afebrile seizures and were receiving anticonvulsant treatment but their parents did not consider them to be epileptic. No seizures were reported in six patients (two boys and four girls). Seven patients had a family history of epilepsy in a first degree relative. Of the 68 patients with Angelman syndrome and epilepsy or recurrent seizures, 51 had a detectable cytogenetic deletion.

Of the patients with Angelman syndrome and epilepsy or recurrent seizures, 65 families attempted to classify seizure types, and recorded seizure frequency, treatment, and treatment responses. Seizures of several types were reported (table 2). Seventy five children had had more than one recorded EEG.

The age at onset of the seizures was $<2$ years in 43 patients and $>2$ years in 25 patients, with an average age at onset of 20 months.

Of the 68 children with seizures, 45 had their last fit in the month preceding the completion of the questionnaire. In nine, the last seizure was longer than two years since completing the questionnaire. In 14 children, no data were given on age at last seizure. Rectal diazepam was given to 47 patients with Angelman syndrome and in 13 patients it was used more than two to three times during the preceding year.

Fifty families recorded their child's current treatment: among these 50 patients valproate (VPA) was used in 13, clonazepam (CZP) in three, clobazam in three, lamotrigine (LTG) in one, a combination of VPA and CZP in 10, a combination of VPA and LTG in eight, a combination of VPA and ethosuximide in three, a combination of LTG and CZP in three, and a combination of CZP and clobazam in one; five patients were taking a combination of three of the aforementioned drugs. Seizure control was 
Table 3 Impact of drug treatment on seizure severity and frequency, and on child's level of alertness and behaviour in 65/68 patients * with Angelman syndrome and epilepsy

\begin{tabular}{|c|c|c|c|c|}
\hline Drug used & Number of fits & Severity of fits & Child's alertness & Behaviour \\
\hline Valproate $(n=45)$ & +22 & +15 & -2 & -4 \\
\hline Carbamazepine $(n=22)$ & -14 & -13 & -13 & -9 \\
\hline Phenobarbitone $(n=5)$ & 0 & 0 & -1 & -2 \\
\hline Phenytoin $(\mathrm{n}=5)$ & +1 & -2 & 0 & -1 \\
\hline Ethosuximide $(n=6)$ & -1 & 0 & -2 & -3 \\
\hline Lamotrigine $(n=13)$ & +12 & +7 & +4 & +5 \\
\hline Vigabatrin $(n=9)$ & -3 & -3 & -8 & -3 \\
\hline Clobazam $(n=5)$ & +2 & +2 & +4 & +1 \\
\hline Clonazepam $(n=23)$ & +17 & +19 & +6 & +3 \\
\hline Gabapentin $(n=2)$ & -1 & 0 & 0 & -1 \\
\hline Nitrazepam $(n=4)$ & +4 & +4 & +3 & +2 \\
\hline
\end{tabular}

If the response was favourable a score +1 was given, unfavourable -1 , and 0 if no effect. The score for each category per specific drug is indicated. A positive score suggests an overall favourable response and a negative score an unfavourable response.

${ }^{\star}$ Only 65 families whose child had epilepsy gave information on the effects of treatment.

reported as good ( $v$ stable or poor) and seizure evolution as improving ( $v$ static or deteriorating) in patients on VPA (12/13), CZP (3/3), clobazam (2/3), LTG (1/1), VPA and CZP (10/10), VPA and LTG (7/8), VPA and ethosuximide (1/3), LTG and CZP (3/3), clobazam and CZP (1/1), and in four of five patients on triple treatment usually with VPA and a benzodiazepine in addition to other antiepileptic drugs.

The effects of individual drug treatment on seizures and the child's alertness and behaviour are shown in table 3 . Factors with a negative effect on seizures were fever, illness, and tiredness. The epilepsy in one child was reported to improve with the ketogenic diet. The most reported side effects were drowsiness and tremor when using VPA and drooling when using CZP.

Parents reported that puberty was associated with overall seizure improvement in three, deterioration in one, and no effect in two patients; data was not given by 14 families with a child at or over 11 years.

One child died at age 4 years as a result of poorly controlled epilepsy.

\section{Discussion}

The overall clinical and cytogenetic data of the 78 patients presented here are mostly consistent with previous reports. ${ }^{1}{ }^{3}$ 7-25

Our patients could be divided into the major types of Angelman syndrome, ${ }^{34}$ namely, patients who were deletion positive (53), patients with uniparental disomy (5), and non-deletion/ non-disomy-type patients (9) (table 1). This suggests that our sample was representative of most other Angelman syndrome populations studied.

We found that Angelman syndrome becomes a more frequent diagnostic consideration between 1 and 4 years of age, as confirmed by other studies. ${ }^{29} 30$ The average age at diagnosis was lower in boys than in girls, a previously unreported observation in large series of patients with Angelman syndrome. ${ }^{10-24}$

Many of our patients had associated medical problems and a significant number required surgery for these problems. Zori et al found similar problems in most of the British patients with Angelman syndrome but in none of the American patients. ${ }^{21}$
The overall reported prevalence of active epilepsy and recurrent afebrile seizures in our patients was similar to other reported series, ${ }^{10-25}$ with most of our patients with epilepsy having a detectable cytogenetic deletion. Also, seven patients had a family history of epilepsy in a first degree relative.

The age at onset of seizures in our group was similar to previous studies of Angelman syndrome, which show that seizures had an onset at age 1-3 years in most patients with Angelman syndrome and at $<12$ months in $14 \% .^{10-25}$

The most common seizure types reported by parents in our group were absence seizures, tonic clonic seizures, drop attacks, and myoclonic seizures (table 2). A few parents reported episodes suggesting non-convulsive status in their child and only a small percentage of them had infantile spasms, convulsive status, and complex partial seizures. The most frequent type of seizures in previous studies on Angelman syndrome were tonic-clonic seizures, atypical absence seizures, myoclonic seizures, tonic seizures, and status epilepticus in childhood; absence status and myoclonic status epilepticus were also found. ${ }^{10-25}$ In adulthood, atypical absence seizures, myoclonic seizures, or a combination of the two are the most prominent, ${ }^{31}{ }^{32}$ as was reported in our four adult patients with Angelman syndrome.

The use of rectal diazepam in our group suggests that epilepsy was an important problem in 47 of the 68 patients with epilepsy and was severe in a further 13 . Of note, one in 10 patients were on treatment with three antiepileptic drugs, where current treatment was recorded.

In our group, anti-epileptic drug treatment with VPA, CZP, and LTG in monotherapy or a combination of VPA and CZP or VPA and LTG was more often viewed favourably and considered to be effective. No specific drug or any combination of drugs was reported to be superior in seizure control in the study by Zori et $a .^{21}$ VPA as monotherapy or combined with clobazam proved effective in the control of both isolated seizures and myoclonic status epilepticus in the series of Viani et al. ${ }^{22}$ In the study of Laan et al the most effective anti-epileptic drugs were phenobarbitone (PB) in monotherapy or VPA in combination with CZP or other benzodiazepines ${ }^{24}$; in adult patients with Angelman syndrome, PB has also been shown to be effective. ${ }^{24}{ }^{31}$ It is of note that piracetam used in association with VPA or benzodiazepines was shown to be an effective and safe drug for symptomatic treatment of cortical myoclonus in five of 11 patients reported by Guerrini et $a l,{ }^{15}$ resulting either in a reduction in myoclonus or improvement in dystonic limb posturing and ataxic gait. None of our patients used piracetam.

In our series, seizures were considered to be increased in frequency and severity with adverse effects reported more frequently with carbamazepine (CBZ) or vigabatrin (VGB) in monotherapy or in combination with other drugs (table 3). It is of note that a similar effect of $\mathrm{CBZ}$ on seizures was reported by previous 
authors but not for VGB. ${ }^{1522}{ }^{24}$ Conversely, seizures in our group were considered to be controlled in frequency and severity by using VPA, LTG, CZP, clobazam, and nitrazepam (NZP) in monotherapy or combined. Parents recorded less side effects on their child's alertness and behaviour with LTG, CZP, clobazam, and NZP than with VPA (table 3 ).

Epilepsy in our group did tend to improve with age; nonetheless, only about half of the older patients (12 of 20 at age $>10$ years) reported overall improvement with time (seizures improvement $v$ static or deteriorating seizures). Furthermore, the four patients older than 20 years in our series were reported not to be free from fits. A few previous studies reported that seizures reduce in Angelman syndrome with age ${ }^{1011}$ and are more easily controlled in later childhood, ${ }^{21} 22$ but more recent, larger surveys $\mathrm{s}^{24132}$ have found that $92 \%$ of the adult patients with Angelman syndrome continue to have epileptic seizures and that seizures play an important role in daily life.

As expected, we found that fever, illness, and tiredness were the most common triggering factors for seizures. It is of note that one child in our series was taking the ketogenic diet and that this diet was effective in improving seizures in this patient.

Overall, the powerful antimyoclonic and anti-absence actions of benzodiazepines, ${ }^{15}$ which are based on their GABAergic properties, were also seen in our patients with Angelman syndrome. In contrast, new anti-epileptic molecules designed for enhancing GABAergic inhibition such as VGB (GABA-T blocker) were not so effective in treating Angelman syndrome associated seizures, as shown in experimental and clinical models of absence seizures. ${ }^{15}$

We acknowledge that this is a selected patient group but hope that the number of responses make the observations useful. The questionnaire was long and relatively complicated but was completed adequately by most parents. The method of distributing the forms combined with their relative difficulty probably accounts for the high number of non-returns; however, the clinical and genetic data provided by parents suggest that this is a representative group of Angelman syndrome patients.

We thank all the parents for enthusiastically filling in the questionnaires. Mr R Allen and Mr A Pryor from ASSERT are gratefully acknowledged for their considerable help and support.

1 Angelman H. "Puppet" children: a report on three cases. Dev Med Child Neurol 1965;7:681-3.

2 McKusick VA. Mendelian inheritance in man. Catalogs of autosomal dominant, recessive, and X-linked disorders, 11th ed. Baltimore: John Hopkins University Press, 1994.
3 Williams CA, Angelman H, Clayton-Smith J, et al. Angelman syndrome: consensus for diagnostic criteria. Am Angelman syndrome: consen
$\mathcal{F}$ Med Genet 1995;56:237-8.

4 Williams CA, Zori RT, Hendrickson J, et al. Angelman syndrome. Curr Probl Pediatr 1995;43:216-31.

5 Kishino T, Lalande M, Wagstaff J. EBE3A/E6-AP mutations cause Angelman syndrome. Nat Genet 1997;15:70-3.

6 Matsura T, Sutcliffe JS, Fang P, et al. De novo truncating mutations in E6-AP ubiquitin-protein ligase gene (UBE3A) in Angelman syndrome. Nat Genet 1997;15:747.

7 Clayton-Smith J. Angelman's syndrome. Arch Dis Child 1992;67:889-91.

8 Kyllerman M. On the prevalence of Angelman syndrome. Am f Med Genet 1995;59:405.

9 Steffenburg S, Gillberg CL, Steffenburg U, Kyllerman M. Autism in Angelman syndrome: a population-based study. Pediatr Neurol 1996;14:131-6.

10 Clayton-Smith J. Clinical research on Angelman syndrome in the United Kingdom: observations on 82 affected individuals. Am F Med Genet 1993;46:12-15.

1 Bottani A, Robinson WP, DeLozier-Blanchet CD, et al. Angelman syndrome due to parental uniparental disomy of chromosome 15: a milder phenotype. Am f Med Genet 1994;51:35-40.

12 Buntinx IM, Hennekam RCM, Brouwer OF, et al. Clinical profile of Angelman syndrome at different ages. Am $\mathcal{F}$ Med Genet 1995;56:176-83.

13 Smith A, Wiles C, Haan E, et al. Clinical features in 27 patients with Angelman syndrome resulting from DNA deletion. 7 Med Genet 1996;33:107-12.

14 Leitner RP, Smith A. An Angelman syndrome clinic: report on 24 patients. $\mathcal{F}$ Paediatr Child Health 1996;32:94-8.

15 Guerrini R, DeLorey TM, Bonanni P, et al. Cortical myoclonus in Angelman syndrome. Ann Neurol 1996;40: 39-48.

16 Bjerre I, Fagher B, Kyding E, Rosèn I. The Angelman or "happy puppet" syndrome. Clinical and electroencephalographic features and cerebral blood flow. Acta Paediatr Scand 1994;73:398-402.

17 Boyd SG, Harden A, Patton MA. The EEG in early diagnosis of the Angelman (happy puppet) syndrome. Eur F Pediatr 1988;47:508-13.

18 Ganji S, Duncan MC. Angelman's (happy puppet) syndrome: clinical, CT scan and serial elctroencephalographic study. Clin Electroenceph 1989;20:128-40.

19 Sugimoto T, Yasuhara A, Ohta T, et al. Angelman syndrome in three siblings: characteristics epileptic seizures and EEG in three siblings: characteristics epileptic seiz

20 Matsumoto A, Kumagai T, Miura K, Miyazaki S, Hayakawa C, Yamanaka T. Epilepsy in Angelman syndrome associated with chormosome 15q deletion. Epilepsia 1992;33: 1083-90

21 Zori RT, Hendrickson J, Woolve S, Whidden E, Gray B, Williams C. Angelman syndrome: clinical profile. $\mathcal{F}$ Child Neurol 1992; 7:270-80

22 Viani F, Romeo A, Viri M, et al. Seizure and EEG patterns in Angelman's syndrome. F Child Neurol 1995;10:467-71.

23 Hou JW, Wang PJ, Wang TR. Angelman syndrome assessed by neurological and molecular cytogenetic investigations. $\mathcal{F}$ Child Neurol 1997;16:17-22.

24 Laan AE, Reiner WO, Arts WFM, et al. Evolution of epilepsy and EEG findings in Angelman syndrome. Epilepsia $1997 \cdot 38: 195-9$.

25 Abstracts for the first national symposium on Angelman syndrome. Eur f Pediatr Neurol 1997;1:A1-9.

26 Ruggieri M, Allen R, Pryor A, McShane MA. Epilepsy and Angelman syndrome. Ann Neurol 1996;40:302.

27 Commission on classification and terminology of the International League against Epilepsy. (1981) Proposal for revised clinical and EEG classification on epileptic seizures. Epilepsia 1981;22:489-501.

28 Commission on classification and terminology of the International League against Epilepsy. Proposal for revised classification of epilepsies and epileptic seizures. Epilepsia 1989;30:389-99.

29 Yamada KA, Volpe JJ. Angelman's syndrome in infancy. Dev Med Child Neurol 1990;32:1005-11.

30 Van Lierde A, Atza MG, Giardino D, Viani F. Angelman's syndrome in the first year of life. Dev Med Child Neurol 1990;32:1011-21.

31 Laan LAEM, den Boer ATh, Hennekam RCM, Renier WO, Brouwer OF. Angelman syndrome in adults. Am $\mathcal{F}$ Med Genet 1996;66:356-60.

32 Sandanam T, Beange H, Robson L, Woolnough H, Buchholz T, Smith A. Manifestations in institutionalised adults with Angelman syndrome. Am $f$ Med Genet 1997;70:415-20. 